\title{
XL. On the hourly alterations of the vapour Atmosphere at Bombay
}

\section{Thomas Hopkins Esq.}

To cite this article: Thomas Hopkins Esq. (1847) XL. On the hourly alterations of the vapour Atmosphere at Bombay , Philosophical Magazine Series 3, 30:201, 246-253, DOI: 10.1080/14786444708645684

To link to this article: http://dx.doi.org/10.1080/14786444708645684

曲 Published online: 30 Apr 2009.

Submit your article to this journal $[\pi$

Џ Article views: 2

Q View related articles $\square$ 
the reasons therein contained, and his determination to adopt the name of Neptune. Prof. Gauss and Prof. Encke have also, as I understand, adopted this name. I have only to add that it is my intention (and I am permitted to say, the intention of $\mathrm{Mr}$. Adams also) to follow the example set by these eminent astronomers.

Cambridge Observatory,

March 22, 1847.

XL. On the Hourly Alterations of the Vapour Atmosphere at Bombay. By Thomas Hopkins, Esq.*

[With a Plate.]

THAVE already availed myself of the observations made 1 at Bombay under the superintendence of Dr. Buist, through a paper on the meteorology of that place by Colonel Sabine, on which I made some remarks that were inserted in the Philosophical Magazine for December 1846. But since those remarks were written I have had transmitted to me, through the kindness of Colonel Sykes, a lithographed copy of the observations themselves, in which are to be found important facts connected with the hourly production of aqueous vapour at Bombay, and its apparent influence on the movements of the barometer.

In addition to the hourly registrations of other meteorological instruments, Dr. Buist has furnished columns of the heights of the wet- and dry-bulb thermometers, showing the hourly depression of the wet below the dry thermometer for each month of the year 184.3. From these columns, it appears that the wet was depressed below the dry instrument, to a certain extent varying both with the time of the day and the season of the year. The depression was the least in the wet season and the greatest in the dry one; and, with reference to the diurnal changes, the depression was generally, but not uniformly, the least about sun-rise and the greatest near to mid-day. These depressions of the wet below the dry thermometer are known to be results of the cooling power of evaporation of water on the bulb of the wet instrument; and the cooling thus produced is proportioned to the extent of evaporation of water that takes place; being small when the evaporation is little, and great when it is much. Thus the registration of the wet-bulb thermometer not only furnishes us with means of determining how far evaporation kept down the temperature of the thermometer exposed to its influence, but

* Communicated by the Author. 
also of ascertaining what were the relative amounts of water evaporated during the different portions of the time,-the cooling being the effect of the conversion of certain quantities of water into aqueous vapour, and being in every separate part of that time proportioned to the quantity converted.

We have also in a separate column of Dr. Buist's returns, the difference between the dry and the wet thermometers; and this difference may be taken to express the relative quantities of water evaporated, and the force of evaporation. From about six in the morning, varying with the season, this difference generally increases until, say twelve or one o'clock in the day, when it declines until the following morning.

As already stated, evaporation is less in the wet than in the dry season; and there is also less difference between the morning and mid-day force of evaporation in the former than in the latter season. The cold part of the year is the period for the land and sea breezes, and also for the extensive daily fluctuations of the barometer; and Dr. Buist says that this season lasts five months, namely, during October, November, December, January and February, forming the winter of the part. But of these October is wavering and uncertain; we may therefore consider the other four months as the season when the sea and land breezes blow in the most decided manner, and in which the greatest daily fuctuations of the barometer take place; it is consequently desirable that we should carefully examine the returns for the whole of these months. To do this, we will take the mean hourly difference between the dry and wet thermometers for each month, and by adding them together and dividing by four, obtain the mean hourly force of evaporation for the winter season. 'This I have done, and the result is given in the following table, to which are added in other columns the mean hourly heights of the barometer, thermometer and wet-bulb thermometer, for the same period, that the whole may be seen at one view in juxtaposition. The same facts are shown in a diagram (Plate IV.), in which the curve of the wet-bulb thermometer is exhibited in accordance with the figures of the table; and also as a base line, from which the distance of the dry thermometer is shown, the intermediate space marking the relative force of evaporation in each hour of the day. 
Diagram

of the hourly heights of the Barometer, the dry Thermometer, the

wet bulb Thermometer; and the relative cunounts of the force of

evaporation at Bombay.

$\begin{array}{lllllllllllllllllllllllll}4 & 5 & 6 & 7 & 8 & 9 & 10 & 11 & 12 & 2 & 3 & 4 & 5 & 6 & 7 & 8 & 9 & 10 & 11 & 12 & 1 & 2 & 3 & \text { thouns }\end{array}$

$82^{2}$

$80^{\circ}$

$79^{\circ}$

$78^{\circ}$

$77^{\prime}$

$76^{\circ}$

75

$74^{\circ}$

73

72

$71^{\circ}$

70

68

$67^{\circ}$

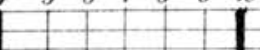
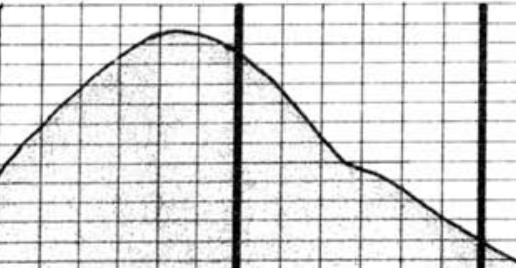

.920

90

890

880

870

.860

.850

.840

.830

.820

.810

120

110

100

8

$7^{\circ}$

$6^{\circ}$

50

$4^{\circ}$

$3^{\circ}$

20

$0^{\circ}$

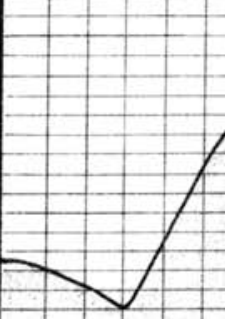


Table of the Mean Hourly state of the following instruments, and of the force of evaporation for the four winter months of 1843 .

\begin{tabular}{|c|c|c|c|c|}
\hline Hours, & Barometer. & Thermometer. & $\begin{array}{l}\text { Wet-bulb } \\
\text { thermometer. }\end{array}$ & Evaporation. \\
\hline $\begin{array}{c}4 \text { A.M. } \\
5 \text { A.M. } \\
6 \text { A.M. } \\
7 \text { A.M. } \\
8 \text { A.M. } \\
9 \text { A.M. } \\
10 \text { A.M. } \\
11 \text { A.M. } \\
12 \text { A.M. } \\
1 \text { P.M. } \\
2 \text { Р.M. } \\
3 \text { P.M. } \\
4 \text { P.M. } \\
5 \text { P.M. } \\
6 \text { р.M. } \\
7 \text { P.M. } \\
8 \text { P.M. } \\
9 \text { P.M. } \\
10 \text { P.M. } \\
11 \text { P.M. } \\
12 \text { P.M. } \\
1 \text { A.M. } \\
2 \text { A.M. } \\
3 \text { A.M. }\end{array}$ & $\begin{array}{l}29 \cdot 838 \\
29 \cdot 848 \\
29 \cdot 867 \\
29 \cdot 889 \\
29 \cdot 911 \\
29 \cdot 928 \\
29 \cdot 928 \\
29 \cdot 911 \\
29 \cdot 884 \\
29 \cdot 853 \\
29 \cdot 827 \\
29 \cdot 817 \\
29 \cdot 815 \\
29 \cdot 817 \\
29 \cdot 835 \\
29 \cdot 854 \\
29 \cdot 874 \\
29 \cdot 886 \\
29 \cdot 887 \\
29 \cdot 881 \\
29 \cdot 873 \\
29 \cdot 862 \\
29 \cdot 848 \\
29 \cdot 841\end{array}$ & $\begin{array}{l}79 \cdot 9 \\
74 \cdot 6 \\
74 \cdot 1 \\
73 \cdot 6 \\
74 \cdot 9 \\
77 \cdot 0 \\
78 \cdot 4 \\
79 \cdot 6 \\
80 \cdot 8 \\
81 \cdot 6 \\
89 \cdot 2 \\
82 \cdot 2 \\
81 \cdot 9 \\
81 \cdot 0 \\
79 \cdot 6 \\
78 \cdot 8 \\
78 \cdot 4 \\
77 \cdot 7 \\
76 \cdot 9 \\
76 \cdot 4 \\
76 \cdot 1 \\
76 \cdot 0 \\
75 \cdot 7 \\
75 \cdot 3\end{array}$ & $\begin{array}{l}68 \cdot 4 \\
67 \cdot 8 \\
67 \cdot 4 \\
67 \cdot 3 \\
68 \cdot 1 \\
68 \cdot 9 \\
69 \cdot 1 \\
69 \cdot 4 \\
69 \cdot 5 \\
70 \cdot 4 \\
71 \cdot 9 \\
72 \cdot 6 \\
72 \cdot 3 \\
72 \cdot 4 \\
72 \cdot 2 \\
71 \cdot 9 \\
71 \cdot 6 \\
70 \cdot 9 \\
69 \cdot 8 \\
69 \cdot 2 \\
69 \cdot 0 \\
69 \cdot 2 \\
68 \cdot 9 \\
68 \cdot 5\end{array}$ & $\begin{array}{c}6 \cdot 5 \\
6 \cdot 8 \\
6 \cdot 7 \\
6 \cdot 3 \\
6 \cdot 8 \\
8 \cdot 1 \\
9 \cdot 3 \\
10 \cdot 2 \\
11 \cdot 3 \\
11 \cdot 2 \\
10 \cdot 3 \\
9 \cdot 6 \\
9 \cdot 1 \\
8 \cdot 6 \\
7 \cdot 4 \\
6 \cdot 9 \\
6 \cdot 3 \\
6 \cdot 8 \\
7 \cdot 1 \\
7 \cdot 2 \\
7 \cdot 1 \\
6 \cdot 8 \\
6 \cdot 8 \\
6 \cdot 8\end{array}$ \\
\hline
\end{tabular}

By examining this table we may see that evaporation at four in the morning is $6^{\circ} \cdot 5$, from which it rises, until at ten o'clock it is $9^{\circ} \cdot 3$, being an increase of $2^{\circ} \cdot 8$; and during this time the barometer is admitted to be raised to the height that it attains, 29.928 inches, through the pressure of the vapour that has been recently produced by evaporation and thrown into the atmosphere.

From ten to twelve o'clock, evaporation, as measured by the difference between the two thermometers, increases up to $11^{\circ} \cdot 3$, being a further rise of $2^{\circ}$; but at the same time the barometer, instead of rising higher, as might be expected, falls no less than $\cdot 044$, as by that hour it sinks to $29 \cdot 884$ inches.

Evaporation becomes rather less active after twelve o'clock; but it still shows great force, and continues to exhibit it till four o'clock, at which time it is $9^{\circ} \cdot 1$, being only $\cdot 2$ less than it was at ten in the morning. Yet during the whole of the time from ten in the morning to four in the afternoon, when evaporation was so energetic, the barometer was falling, and sunk no less than 113. What then became of the vapour 
that was produced and discharged into the atmosphere within this period? The quantity passed into the atmosphere in the six hours must have been large, it being the product of an average evaporation of $10^{\circ} .3$ for the whole time; whilst the average for the previous six hours was only $7^{\circ} .3$ when the barometer was rising. Now, can it be supposed that a comparatively small additional quantity of vapour raised the barometer considerably from four to ten in the morning, and a further large addition to that quantity, acting in the same way from ten to four in the afternoon, not only ceased to raise it, but was attended by a fall of that instrument to an extent greater than the previous rise,-without some other cause coming into operation? It cannot be maintained that the increase of surface thermometric temperature had but little counteracting effect before ten, and great counteracting effect after that time until four o'clock. For the rise of the thermometer from four to ten in the morning was little less than it was from ten in the morning to two in the afternoon, - the time of the highest temperature, -it having risen so much as $3^{\circ} .5$ in the former, and only $3^{\circ} .8$ in the latter period. And it should be remembered that evaporation from ten to four was constantly adding fresh vapour to that which was previously in the atmosphere, where the whole was accumulating, and pressing with its aggregate weight on the barometer. There is, therefore, in the facts presented to us in the tables, no countenance for the supposition that temperature, as measured by the thermometer near the surface of the earth, counteracted the increase of vapour pressure after ten o'clock, and caused the fall of the barometer.

It is however sufficiently evident, from the facts given, that the vapour produced in the morning constituted the material which supplied the heat that at this time rendered the atmosphere warm and light in the locality, and caused the barometer to fall.

When the sun advances above the horizon it warms the surface of the globe, and not only increases evaporation of water, but heats that portion of the atmospheric gases that is near the surface,-which portion rises probably in separate streams or columns, - cooler columns at the same time descending to the surface and taking the place of the warmer. This process goes on as the sun rises higher, until at some particular time, depending on the locality and season, the ascending columns reach a height sufficient to enable the expanding gases to cool and condense some of the vapour which is intermingled with them. This ordinarily takes place from nine to eleven o'clock, or say at ten in the morning, from 
which hour condensation is warming the atmospheric mass in the locality. This warmed mass, a mixture of gases and vapour, as it ascends is acted on by the different laws of cooling, of condensation, and of expansion by heat, which the constituent parts of the atmosphere obey; and the result is the formation of a buoyant column of cloud, of greater or less thickness, according to the quantity of vapour that has been condensed. The whole local column being thus made lighter by the liberated heat, it presses with less force on the surface of the earth, and consequently on the barometer. This diminished pressure is however effected through the liberated heat driving a portion of the material of the atmosphere, the gases, from the heated part to other parts of the atmospheric space; and thus we find that the heat just liberated by the condensation of vapour counteracts the increased pressure of the aqueous matter, which is at the same time passing into the atmosphere in the form of vapour. For it is here contended that the vapour that had been produced from four to ten in the morning, is, soon after the last-named hour, not only raised but condensed,--deprived of a part of its heat, and converted into minute particles of water, which float in the gaseous atmosphere as a cloud; and as such, undoubtedly form a part of the whole atmosphere and contribute to its weight. It is not therefore through a reduction in the quantity of aqueous matter in the local atmosphere, at this period of the day, that the barometer falls; but that fall is caused by the expanding power of liberated heat driving from the heated vertical column a part of the ponderable gases which previously existed within it, and, in that way, by removing a part of the material of the atmosphere, causing the remainder to press with less weight on the barometer.

The quantity of vapour that passes daily into the atmosphere while the temperature is rising, and which does not fall as rain, is returned to the earth as dew on its surface; and thus an equilibrium is established between the production and the condensation of vapour; but this does not take place during the period of which we have been treating, that is to say, from four o'clock in the morning to four in the afternoon. Vapour is not daily abstracted from the atmosphere by the formation of dew on the surface of the earth, until the barometer ceases to fall at four o'clock in the afternoon. At present we have to consider the influence of vapour during two periods of six hours each, - that in which the barometer is rising from four to ten in the morning, and that in which it is sinking from ten to four in the afternoon: and it has been shown that aqueous matter during the whole of this time was 
increasing in quantity and accumulating in the atmosphere; and as far as that matter influenced the atmosphere, it must have increased its weight. The aggregate pressure of aqueous matter did not cease to increase at ten o'clock in the morning, when the barometer began to fall; that fall was produced by a new cause which then came into operation in the locality, namely, the expanding and displacing power of liberated heat.

It will probably be asked whether cloud forms near to, or over Bombay, after ten o'clock, and increases till four, as assumed? and to this inquiry I cannot give an answer that is likely to be quite satisfactory, not having full information on the subject. Dr. Buist, in his introductory remarks, does not particularly notice the formation of clouds within that portion of the day. In the hourly-observation tables there is a column for describing the appearance of clouds; and the entries in that column show that the cumulus, the cirro-cumulus, and the cirro-stratus were often formed, but they are not described in such a way as would justify me in adducing them as proofs of the agency here ascribed to them, although they do furnish rather strong presumptive evidence on the subject.

Clouds form pretty freely from ten in the morning till four in the afternoon, whilst from ten at night to four in the morning the atmosphere is represented as being generally clear : and taking the accounts given of the elouds during the two periods, we are fully authorized to say that they formed and remained suspended in the air during the former period, and were dissolved before the arrival of the latter period; showing that there were daily formation of cloud by condensation of vapour, and daily dissipation of those clouds by evaporation.

But in addition to the daily formation of visible clouds, there are indications that condensation takes place, but only to such an extent as to produce a haziness or misty appearance in the sky; and if this process is carried on until a considerable height is attained, it must warm the atmospheric mass and lighten it. Indeed, at the commencement of the process of gradual condensation, the cloud that is thereby formed is not seen; as it is only when a sufficient stratum of floating globules of water is produced that the cloud becomes visible. The first slight falling of the barometer before rain is probably caused in this way.

Judging from analogous cases, it may be presumed that palpable daily clouds at Bombay were first formed near the high ground to the east of that place, as such clouds in other similar places generally form near to, or against the sides of hills. Our old navigators have described such formations in 


\section{$252 \mathrm{Mr}$. T. Hopkins on the Vapour Atmosphere at Bombay.}

many parts of the world; but the following account given by Hutchison of Glasgow, contains a description of that which ordinarily takes place in localities similar to that of Bombay, although the distance of the mountains from the places of observation in the two cases, and the influences of the tradewinds may modify the process. Mr. Hutchison says that " the formation of clouds is finely illustrated by the phænomena daily exhibited during the dry season over what are called the Liguana, or Port Royal Mountains in the island of Jamaica. These mountains are situated about four or five miles to the north-east by east of Kingston, the principal port in the island, and their height above the level of the sea is about 4000 to 5000 feet. During the dry season, from the beginning of November till the middle of April, the sea and land breezes alternately succeed each other with an intermediate interval of atmospheric stillness, in the following manner. From sun-rise till about ten o'clock in the forenoon it is usually perfectly calm. About ten o'clock, the sea breeze, blowing at Kingston from the east, or a little to the south of east, commences and continues till about half-past three in the afternoon, when it gradually and entirely subsides." Again, "About eleven o'clock every forenoon, or between that and mid-day, the summits of the Port Royal Mountains begin to be covered with clouds, which, though thin, fleecy and transparent at first, gradually increase in density till about one o'clock. By this time the upper portions of the mountain, when viewed from Kingston, seem to be wholly enveloped in dense clouds, rain is apparently falling in torrents, flashes of lightning are seen, and the sound of distant thunder is heard. About half-past two o'clock in the afternoon, the clouds, gradually diminishing in density, begin to quit the mountains; so that their summits again become visible, as in the morning, and so continue till about eleven o'clock the following day. The clouds after quitting the mountains rise gradually to a greater altitude and float very slowly westward, assuming as they proceed the appearance of large heaped-up cumuli." See Hutchison on Meteorological Phænomena, p. 64.

The general trade-wind about Jamaica was from the east, and it bore the ascending clouds to the west in the afternoon: the trade-wind at Bombay was ordinarily from north of west, and it would doubtless modify the influence of the mountains on the clouds formed in the part. Were meteorological instruments corresponding with those kept at Bombay placed to the east of that place at the rise of the hills, and registered in the same way as at Bombay, it would probably throw further light on the daily atmospheric disturbances in this part 
of the world, and enable us to form a better judgement of the alterations which take place in other parts. The daily range of the barometer at Poonah, which is on the eastern side of the ridge of the Ghauts, and far from the sea, is about as great as it is at Bombay. There can be no sea breeze at Poonah, as the mountain range is between it and the sea; but are there not diurnal winds of similar character to those on the coast? Corresponding registrations at Poonah, Bombay, and some intervening place on the west of the Ghauts, might furnish valuable additions to our stock of meteorological information, and cnable us to trace the operating causes as they pass from one meridian to another, and might thus furnish us with more conclusive evidence of the nature and causes of the hourly alterations which occur in the atmosphere than any that can be adduced at present.

XLI. Remarks on the Extractive Material of Urine, and on the Excretion of Sutphutr and Phosphorus by the Kidneys in an unoxidized state. By Edmund Ronalds,Ph.D., Giessen*.

SOME months back, at the instigation of Dr. Golding Bird, I undertook some experiments to ascertain whether, in cases of diseased and imperfect function of the lungs or liver, when the normal quantity of carbon could not be discharged from the system by those channels, the kidneys undertook an extra duty, and whether under such circumstances an excess of carbon could be shown in the urine above that usually secreted under healthy conditions.

Should this question be answered in the affirmative, and should it be found that a larger amount of carbon was excreted by the urine in persons affected with such diseases, a practical application might reasonably be made of the fact. For by stimulating the kidneys to still greater exertion, the amount of work required of the lungs or of the liver could be lessened, and thus a better chance offered them of being restored to a healthy state.

The method proposed for solving this problem was, to precipitate the urine of different patients suffering from diseases of the kinds mentioned, with basic acetate of lead, keeping it slightly alkaline by the addition of a few drops of ammonia, then to ascertain the amount of organic matter contained in the precipitate, and in particular the amount of carbon, and lastly to compare these quantities with those obtained in a similar manner from the urine of healthy individuals.

* From the Philosophical Transactions for 1846, part iv.; having been received by the Royal Society April 25, and read June 18, 1846. 